\title{
A dialética do mando em colônias
}

\section{The dialectics of power in colonies}

\author{
Paulo Cavalcante \\ Departamento de História da Universidade Federal do \\ Estado do Rio de Janeiro (UniRio) \\ Rua Torres Homem, 538/401 - Vila Isabel \\ 20551-070 Rio de Janeiro - RJ - Brasil \\ timaeus@globo.com
}

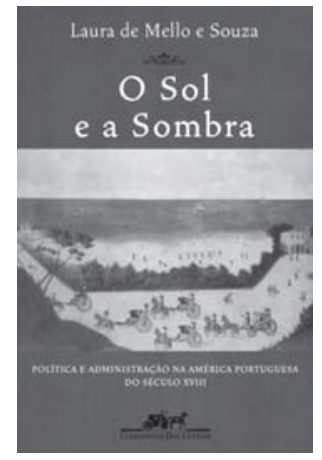

Souza, Laura de Mello e. O sol e a sombra: política e administração na América portuguesa do século XVIII. São Paulo: Companhia das Letras, 2006. 505p. il.
$\mathrm{O}$ sol, metáfora do poder temporal dos reis. A sombra, malha administrativa esticada conforme a distância que, por sua vez, distorcia práticas, tradições e ordens. O que era mandar e governar na América portuguesa? Eis a questão instilada no título desse belo livro de Laura de Mello e Souza.

A autora, acostumada a produzir livros de referência, como Desclassificados do ouro (1982) e O diabo e a Terra de Santa Cruz (1986), apresenta-nos agora o resultado de uma retomada, de uma viragem e da consolidação de sua trajetória profissional. Depois de haver-se experimentado com sucesso no campo da história social, com Desclassificados, e na história cultural, com $O$ diabo, retoma o primeiro num movimento diferenciado, virando e incorporando suas reflexões para produzir uma síntese amadurecida dos seus estudos sobre colonização da América e história moderna, desta feita no leito da história político-administrativa renovada.

A análise empreendida pensa dialeticamente o mando metropolitano, isto é, sua natureza política e prática administrativa, com as devidas ambigüidades, nuances e contradições da sua manifestação em formações sociais específicas sob o nexo colonial. Sem absolutizar nenhum aspecto, o texto 'joga' - a palavra jogar é utilizada de forma recorrente - e embala a reflexão de modo a dar conta da realidade cambiante, materializada nas desafiadoras tentativas de reiteração da ordem metropolitana na América que, no limite, geraram uma 'outra' totalidade.

Dividido em duas partes, na primeira, "Enquadramentos", tem curso o debate historiográfico, o arcabouço conceitual, a perspectiva adotada e o contexto geral, e na segunda, "Indivíduos", são examinados itinerários administrativos e trajetórias pessoais de seis governadores coloniais em diferentes conjunturas e múltiplas relações no âmbito do império colonial. É nessa última parte que a autora afirma haver realizado uma 'etnografia da prática governativa', tal como realizara antes uma 'etnografia da prática mágico-religiosa' no capítulo final de $O$ diabo. 
O primeiro capítulo, "Política e administração colonial: problemas e perspectivas", atualiza um debate que remonta ao final da década de 1970, sobre como interpretar a economia e a sociedade da América portuguesa, com origens e repercussões tanto dentro como fora do marxismo, pondo em xeque a idéia de 'sentido da colonização' (Caio Prado Jr., 1942) e o conceito de 'antigo sistema colonial' (Fernando Novais, 1974, 1979).

Como conseqüência das críticas lançadas, mercantilismo, absolutismo, acumulação primitiva de capital, economia-mundo e colonialismo moderno - as relações de exploração entre metrópole e colônia - perdem o condão de conceitos-chaves. Outro quadro explicativo se insinua, crítico da chamada teoria da dependência, reconfigurando as relações entre centro e periferia para percebê-las no âmbito das relações imperiais, dadas no interior de cada império ultramarino, como extensões de suas sociedades de Antigo Regime.

O ponto de inflexão mais recente desse debate se dá com o texto "Bases da materialidade e da governabilidade do Império" (2000), de João Fragoso, Maria de Fátima Silva Gouvêa e Maria Fernanda Baptista Bicalho. Pacto, negociação política e estratégias de poder ganham relevo na interpretação da história política e administrativa dos impérios, ferindo de morte o 'colonial' do pacto. É digno de nota que a edição brasileira (2002) do clássico de Charles Boxer The portuguese seaborne empire (1969) exiba a tradução literal do título - O império marítimo português - e não o título adotado na edição portuguesa (1981) - O império colonial português. O império sobrevive à colônia.

Quando passa em revista a historiografia dedicada à política e à administração, Laura de Mello e Souza esquadrinha os autores sobre os quais se ergue "a nova voga do império", arrojando sua verve crítica sobre Antônio Manuel Hespanha. Reconhece neste preciosa contribuição para o entendimento do Estado português e da administração do império, ao fornecer a matriz teórica das lógicas de um outro tempo com base na conhecida crítica do paradigma estatal - preservandonos do pecado do anacronismo. No entanto, detecta alguns "problemas que a aplicação indiscriminada da análise de Hespanha ao contexto brasileiro pode trazer" (p.52).

Atenta às invasões da ideologia na teoria, argúi a visão conservadora de Otto Brunner, importante representante da historiografia constitucional alemã, corrente à qual se filia Hespanha. Em seguida, nota a "supervalorização dada por este aos textos jurídicos" (p.55) e, citando Caio Prado Jr., lembra que "o mundo das colônias não pode ser visto predominantemente pela ótica da norma, da teoria ou da lei, que muitas vezes permanecia letra morta e outras tantas se inviabilizava ante a complexidade e a dinâmica das situações específicas" (p.56). Mas não apenas o mundo das colônias; o europeu também não podia, pois, conforme Aléxis de Tocqueville: "Eis todo o Antigo Regime e sua caracterização: uma regra rígida e uma prática flácida".

Por fim, e não menos importante, clama pela centralidade do escravismo na interpretação da condição colonial. "Leis, relações de produção, hierarquia social, conflitualidade, exercício do poder, tudo teve, no Brasil, que se medir com o escravismo" (p.57). Aqui a contri- 
buição de Hespanha manqueja. E manqueja por não dar conta das peculiaridades da prática do poder num mundo tão distinto porque em situação colonial escravista. Em poucas palavras: "A especificidade da América portuguesa não residiu na assimilação pura e simples do mundo do Antigo Regime, mas na sua recriação perversa, alimentada pelo tráfico, pelo trabalho escravo de negros africanos, pela introdução, na velha sociedade, de um novo elemento, estrutural e não institucional: o escravismo" (p.68).

Os já citados João Fragoso, Maria Fernanda Bicalho e Maria de Fátima Gouvêa, enquanto organizadores do livro Antigo regime nos trópicos (2001), são confrontados com duas críticas. Primeiro, a falta de clareza no uso de conceitos como 'economia do bem comum' e 'economia política de privilégios', que a autora atribui provavelmente à imprecisão do próprio Hespanha quando se vale do conceito de 'economia do dom', deslocando a análise feita por Marcel Mauss de um mundo desmonetarizado e lançando-o nos tempos do capitalismo em formação. Segundo, com o programa dos autores de "romper com uma visão dualista e contraditória das relações metrópole-colônia", porque, conforme Laura de Mello e Souza, "a contradição, enquanto princípio, define-se como antítese do dualismo. Em situação colonial, onde as contradições são particularmente exacerbadas, a convergência ou coincidência de práticas e interesses é não raro antes forma que conteúdo" (p.60). Para ela, "o entendimento da sociedade de Antigo Regime nos trópicos beneficia-se quando considerada nas suas relações com o antigo sistema colonial" (p.67).

Este é mais um ponto inspirado na obra de Fernando Novais: "o sentido que as relações entre as partes do sistema colonial adquirem no plano específico e no geral, e como se transformam e se ressignificam" (p.76). O sol e a sombra, em si, é a realização desse propósito. Incorpora as recentes contribuições do 'grupo português' - Nuno Gonçalo Monteiro, Mafalda Soares da Cunha, Ângela Barreto Xavier e Fernanda Olival -, mostrando que "o Império foi um dos espaços privilegiados para se obter a recompensa do serviço real" (o chamado sistema de recompensas ou economia das mercês), e as faz dialogar criticamente com uma tradição brasileira de pensamento, exemplificada com Caio Prado Jr., Sérgio Buarque de Holanda, Raymundo Faoro e o próprio Fernando Novais. O resultado é o jogo dialético entre as partes e o todo, eliminando a oposição mecânica entre metrópole e colônia, indo além da relação Brasil-Portugal e procurando, enfim, entender a totalidade do sistema.

O segundo capítulo examina a conjuntura do início do século XVIII, analisa as formulações políticas do conselheiro Antônio Rodrigues da Costa - em particular os perigos internos e externos à manutenção do reino e das conquistas - e as considerações do autor de Cultura e opulência: "Antonil foi mais um a ver unidade nas partes da América portuguesa, que chamou de Brasil, considerando as drogas e as minas como cimento a uni-las e expressando, a seu modo, o que, mais de dois séculos depois, seria qualificado [por Caio Prado] de sentido da colonização" (p.100). No capítulo 3 enfrenta o processo de constituição da controversa memória paulista que, "como boa ideologia, desbastou as con- 
tradições inerentes ao papel histórico dos habitantes de São Paulo e sublinhou, isolando-as, as virtudes que, até então, nunca haviam se mostrado em separado dos vícios" (p.147). No quarto capítulo discorre sobre a especificidade da sociedade mineira, os modelos de nobreza vindos da metrópole e o significado de ser nobre em Minas, concluindo o enquadramento geral.

O quinto capítulo se ocupa da trajetória do conde de Assumar e abre a segunda parte do livro, "Indivíduos". Centrado na interpretação do Discurso histórico e político sobre a sublevação que nas Minas houve no ano de 1720, cuja autoria atribui ao conde e a dois jesuítas, e lidando com outro tema caro à memória nacional, a Revolta de Filipe dos Santos, a autora vê "no Discurso, em vez de 'libelo monstruoso', um interessante tratado político da época, manifestação peculiar num universo que, como o luso-brasileiro, foi avaro em textos do gênero, e ímpar no fato de partir da prática governativa e do que ela impunha no dia-adia - sobrepujar distâncias com decisões rápidas; sufocar levantes que ameaçavam o poder do rei - para, com base em tradições do pensamento europeu, ensaiar uma teoria do mando em situação colonial" (p.251). Da prática à teoria, embora estranhando a vida no trópico, Assumar "não se furtou ao desafio de pensar sobre suas contradições".

O capítulo 6 trata da atuação ambígua e do jogo duplo de um exgovernador da Colônia do Sacramento, Sebastião da Veiga Cabral. O que mais interessa à autora são as constantes referências a maquinações no reino e suas repercussões nas colônias americanas. Uma densa rede de relações conectava o centro do Império e suas partes, carregando conflitos e transmitindo experiências administrativas.

A narrativa da morte de Rodrigo César de Meneses, ex-governador de São Paulo e governador de Angola, com a singela "aptidão para bem roubar enquanto bem servia" (p.302), dá início ao sétimo capítulo, em que explora a dialética entre o mar e o sertão. O oitavo capítulo analisa a trajetória do governador Luís Diogo Lobo da Silva, exemplarmente criterioso na produção de situações e documentos comprobatórios capazes de lhe assegurar a devida remuneração por seus serviços. O penúltimo capítulo esmiúça a vida de dom Antônio de Noronha, governador das Minas nomeado em 1774, aquele cuja singularidade "reside sobretudo na coragem de ser original, de pensar com a própria cabeça e segundo os dados empíricos que o dia-a-dia da governança lhe propiciava, revendo, quando preciso, posições tomadas anteriormente" (p.355). O exame da prática governativa de dom Antônio propicia o retorno analítico de Laura de Mello e Souza a um dos pontos centrais do seu livro Desclassificados do ouro: a idéia da utilidade dos vadios.

O tempo fulgurante do ouro em profusão havia passado e os governantes buscavam alternativas para a queda nos rendimentos. Para tal, dom Antônio valeu-se das energias da terra, daquelas gentes não só desprovidas das 'qualidades' dignas dos agentes do Estado numa sociedade de Antigo Regime, como objeto mesmo da sua repressão. Em carta ao vice-rei justificou a decisão: "Pelo que pertence aos vadios, permita-me V. Excia. que eu lhe diga que sendo esta qualidade de gente ódio de todas as nações civilizadas, e para cuja extirpação se tem tantas vezes legislado, não podem ser aplicáveis as regras comuns relativas 
a este ponto no território desta capitania; porque estes vadios, que em outra parte seriam prejudiciais, se fazem aqui úteis. Eles, excetuando um pequeno número de brancos, são todos mulatos, mestiços, cabras e negros forros: por estes atrevidos homens é que se mandam povoar os remotos sítios do Cuieté, Abre-Campo e outros..." (p.377).

$\mathrm{O}$ que era mandar e governar na América portuguesa? O governador colonial, representante do rei, para cumprir o seu dever, precisava negar a ordem social que representava. A reiteração do todo só se perfazia mediante a diferenciação das partes. Para a autora, "a idéia da utilidade dos vadios das Minas foi, assim, fruto de uma reflexão sofisticada sobre as peculiaridades do meio natural e dos habitantes da capitania: a prática administrativa levava a concepções sobre a ordem social, e a sensibilidade de Dom Antônio impunha que reformulasse idéias preconcebidas com flexibilidade maior do que outros seus companheiros na função da governança" (p.378).

O livro se consuma com um canto, o Canto genetlíaco, que Inácio José de Alvarenga Peixoto compôs por ocasião do nascimento de dom José Tomás, filho do governador que sucedeu a dom Antônio, dom Rodrigo José de Menezes. A autora faz uma incursão pela sociabilidade literária mineira em busca das diferenças, das especificidades, das contradições e dos conflitos em tempos de crise sistêmica.

A trajetória de dom José Tomás oscila de um mundo a outro. Entre o seu nascimento, em 1782, e a sua morte, em 1819, os mundos se transmudaram. Seguindo-lhe os passos, pode-se acompanhar a tessitura cotidiana de identidades ao sabor do balanço ambivalente e ambíguo de dois impérios.

Como diz Walter Benjamin: “Quem escuta uma história está em companhia do narrador; mesmo quem a lê partilha dessa companhia". Lendo $O$ sol e a sombra para fazer-lhe a resenha, magnetizado pela presença de Laura de Mello e Souza, atendi a outra recomendação de Benjamin e 'escovei a história a contrapelo', relendo-o de trás para frente. Encontrei, então, uma vez mais, o mesmo humanismo, rigor e coerência. Obra de mestre. 


\section{REFERÊNCIAS BIBLIOGRÁFICAS}

Charles, Boxer

2002

Charles, Boxer

1981

Boxer, Charles 1969

Fragoso, João; Gouvêa, Maria de Fátima S.;

Bicalho, Maria Fernanda

B. (Org.)

2001

Fragoso, João; Gouvêa, Maria de Fátima S.;

Bicalho, Maria

Fernanda B. 2000

Novais, Fernando 1979

Novais, Fernando 1974

Prado Jr., Caio 1942

Souza, Laura de Melo 1986

Souza, Laura de Melo 1982
O império marítimo português.

São Paulo: Companhia das Letras.

O império colonial português.

Lisboa: Edições 70.

The Portuguese seaborne empire, 1415-1825.

Londres: Hutchinson.

O Antigo Regime nos trópicos: a dinâmica imperial portuguesa (séculos XVI-XVIII). 1.ed. Rio de Janeiro: Civilização Brasileira.

Uma leitura do Brasil colonial: bases da materialidade e da governabilidade no Império. Penélope, Lisboa, v.23, p.67-88.

Portugal e Brasil na crise do antigo sistema colonial.

São Paulo: Hucitec.

Estrutura e dinâmica do antigo sistema colonial.

São Paulo: Brasiliense.

Formação do Brasil contemporâneo.

São Paulo: Brasiliense.

O diabo e a Terra de Santa Cruz.

São Paulo: Companhia das Letras.

Desclassificados do Ouro: a pobreza mineira do século XVIII. Rio de Janeiro: Graal. 